Soft tissue sarcomas account for $1-2 \%$ of all tumours. About 10 to $20 \%$ of these tumours are localized in the retroperitoneal space. The basis of diagnostics is radiological examinations. The treatment of retroperitoneal sarcomas is based on surgery combined with radiotherapy and chemotherapy. The patient, aged 45 , with a histopathological diagnosis of liposarcoma, was operated on with brachytherapy and radiotherapy. After 18 months the recurrence of the disease was diagnosed in $\mathrm{CT}$ examination. Before chemotherapy, CT and MR examinations and biopsy had been done with no recurrence result. The above-mentioned changes were found to be the post-treatment changes. The current condition of the patient is good; there is no recurrence and no remote metastasis.

Key words: liposarcoma, "en bloc" operation, CT, MR examination.

\section{Controversies and difficulties of CT and MR imaging evaluation - on the basis of a case study of liposarcoma in the retroperitoneal space}

\author{
Magdalena Fundowicz'1 Mariusz Uściniak²
}

1Department of Radiation Oncology, Greater Poland Cancer Centre, Poznan

2Department of Radiology, Greater Poland Cancer Centre, Poznan

\section{Introduction}

Soft-tissue sarcomas are rare tumours, constituting 1-2\% of all malignant tumours. Approximately $10-20 \%$ of these tumours are located in the retroperitoneal space. Out of all retroperitoneal tumours, those most likely to occur are liposarcoma, leiomyosarcoma, and malignant schwannoma [1].

Because of its location, slow growth, and associated with it a long latency period, retroperitoneal sarcomas reach large sizes. Peak incidence falls between 40 and 60 years of age. The most common symptoms include pain and enlarged abdomen circumference; gastrological symptoms occur sporadically. Retroperitoneal sarcomas often infiltrate adjacent tissues and organs such as kidney, colon, duodenum, pancreas, and large vessels. Lymph node metastases are rare [1, 2].

The basis of diagnostics is radiological tests: abdominal ultrasound, computed tomography or magnetic resonance. Biopsy made under the control of the ultrasound image or CT scan allows diagnosis by histopathology. Sometimes it is difficult on the basis of biopsy to determine the type of sarcoma and its degree of malignancy. That is why some surgeons recommend laparotomy with biopsy [3-5].

Treatment of retroperitoneal sarcoma is based on a combination of surgical treatment with radiotherapy and chemotherapy.

The aim of surgery should be to achieve complete tumour removal with a wide margin of healthy tissue.

In the case of retroperitoneal sarcomas, it is often necessary to perform resective surgery, type "en bloc", including the removal of infiltration of tissues and organs such as stomach, small intestine, large intestine, pancreas, spleen, kidney, and part of the liver. In specialized centres, this type of surgery is performed in $83 \%$ of cases $[4,6,7]$.

In the case of non-radical surgery with low differentiation of tumour, radiotherapy is used complementarily; the total dose should be above 50 Gy. Increasingly, intraoperative brachytherapy is combined with pre-or postoperative radiotherapy to reduce side effects of high dose irradiation of the abdominal organs and reduce the number of local recurrences. Using only intraoperative irradiation is insufficient $[8,9]$.

There have been no beneficial effects of chemotherapy on overall survival.

\section{Case report}

A woman aged 45 was admitted to the family doctor because of pain in the left lumbar area, with local spreading. Ultrasound of the abdomen revealed a small degree of slack in the left kidney. Basic laboratory tests were without deviation. Expanded diagnostic tests using abdominal CT were performed; they showed a focal lesion of $6 \mathrm{~cm}$ with fuzzy contours in the lower part of 


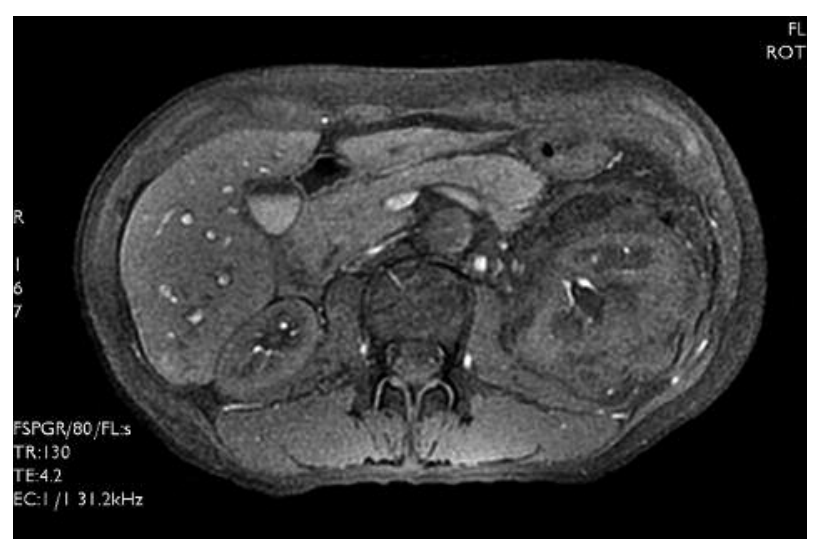

Fig. 1. MR-02/2005

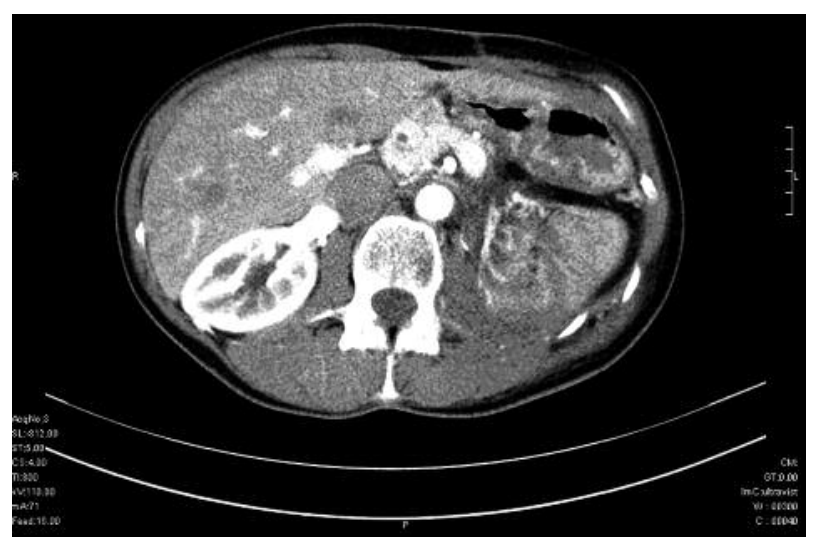

Fig. 3. CT-01/2007

the left kidney, with infiltration of the psoas major muscle, and spleen displaced upwards. The patient was referred to the Urological Clinic in Poznan, where she underwent radical removal of the tumour; histopathological diagnosis was fibromyxoid liposarcoma G1. After a month, a control MRI examination of the abdominal region was performed, which showed a large retroperitoneal tumour (Fig. 1). The patient was referred to the Oncology Centre in Warsaw, where she had further surgery, "en bloc", consisting in removal of the tumour, left kidney, spleen, and part of the pancreas with a margin of healthy tissue (total $20 \mathrm{~cm}$ ). During the procedure, intraoperative brachytherapy was performed, with the dose of 20 Gy. Histopathological examination of the postoperative material confirmed liposarcoma G1.

After the surgery the patient received supplementary teletherapy. The total dose was 50.4 Gy (1.8 Gy fractional dose).

The patient was in good condition after the treatment. The patient remained under strict control of oncologists.

The tomographic tests of the abdomen showed no recurrence of cancer (Fig. 2).

One year after the1 completion of the treatment the patient had gastric complaints - intra-abdominal pain, anorexia, constipation, vomiting. Gastric ulcer was diagnosed with the presence of Helicobacter pylori; a conservative treatment was implemented - with no improvement.

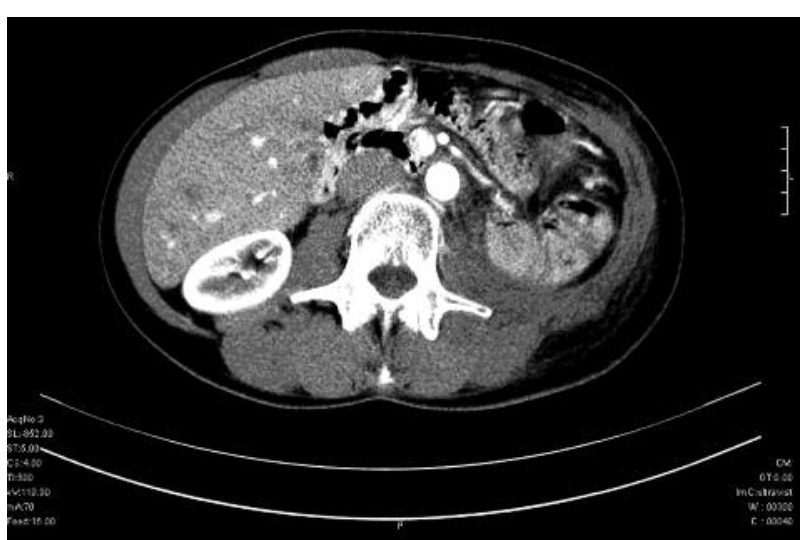

Fig. 2. CT-02/2006

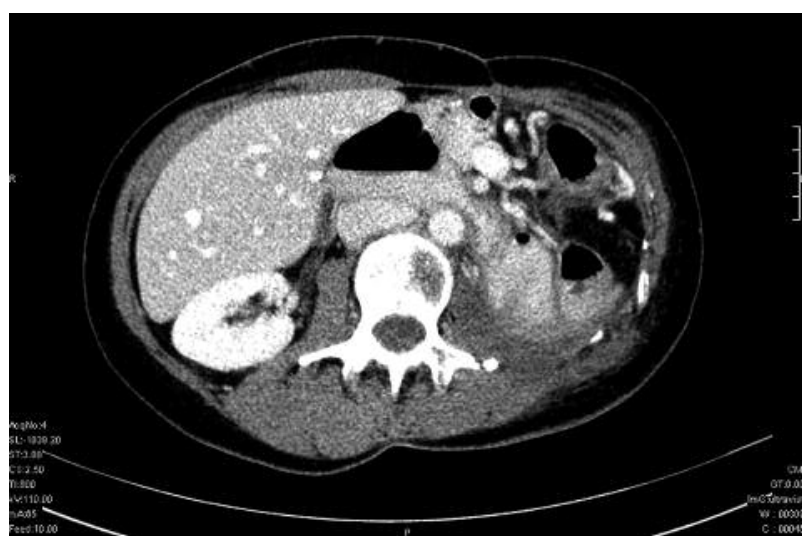

Fig. 4. CT-11/2007

The patient was admitted to the Department of Surgery of the University of Medical Sciences in Poznan with suspected intestinal obstruction. Laparotomy was performed. Post-radiation small bowel obstruction was diagnosed; gastroenterostomy and Brown's entero-enterostomy anastomosis was performed. In the collected material, in the histopathological examination no tumour cells were found.

The patient remained under oncological control. Her general condition was good, and additional examinations were without deviation.

After half a year, more monitoring abdominal CT examinations were performed. In the place where the left kidney had been removed, an extending downward infiltration was detected - the image suggested recurrent tumour (Fig. 3). The patient was disqualified from repeated surgery because of large changes of over $10 \mathrm{~cm}$; she was qualified for symptomatic treatment. The patient was in good condition, did not report any pain, and additional examinations did not detect any symptoms of recurrence of the disease. Repeat CT examination performed after another 6 months confirmed local recurrence, but showed no progression of the described infiltration (the change was not enlarged). Due to the good general condition of the patient and the continuing changes in radiological tests, the patient was referred to the chemotherapy clinic for consideration of chemotherapy treatment with cytostatics. Before the treatment it was de- 


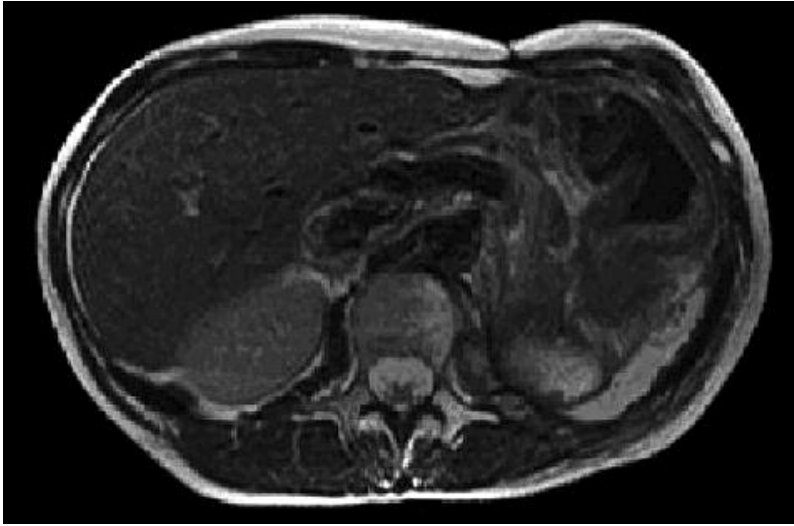

Fig. 5. $M R-02 / 2008$

cided to perform another abdominal CT examination. Three months after the last examination, abdominal CT was performed - the described substance extending from the level of the left part of the diaphragm along the lateral edge of the spine and psoas major muscle was reduced, and did not show signs of growth after application of the contrast agent (Fig. 4). The patient was qualified for the biopsy under the image of the CT of the changes; diagnostic biopsy material was not obtained during the histopathological test. Given the ambiguous picture, it was decided to implement magnetic resonance imaging. Thirty months after the treatment in MRI was finished (Fig. 5) the recurrence of the disease was not confirmed. The treatment with cytostatics was abandoned.

Re-analysis of radiographic images did not show any changes in favour of recurrent disease - the described changes seem to be scar changes; they do not show contrast intensification in CT or MR.

Currently, the patient's condition is good, laboratory tests are without deviation, there has been no evidence of recurrence, and no distant metastases (liver, lungs).

\section{Discussion}

The basic treatment of liposarcoma is surgery and the lack of completeness of resection significantly worsens the prognosis. Five-year survivals after resection of the tumour range from 25 to $70 \%$ and the recurrence rate is estimated at $40-80 \%$ [10-12]. Distant metastases to the liver or lungs are rare. The most common cause of treatment failure is local recurrence.

Overall survival is connected with the degree of tumour malignancy. Tumours with a high degree of malignancy are associated with 3-6 times higher risk of death than tumours with a small or medium degree $(G 2, G 1)$ [13].

The indications for radiotherapy are non-radicalness of the surgery, recurrence, and a high degree of malignancy [14].

Research is being conducted on the effects of chemotherapy, using doxorubicin or imatinib; however, no positive impact on the overall effect of treatment has been found. The use of perioperative chemotherapy was unsuccessful [4, 9].

Encouraging results in survival were obtained by using intraoperative brachytherapy and external beam therapy $[15,16]$.

Conducting randomized trials in patients with retroperitoneal sarcoma is to contribute to determining the type of therapy used for healing.
It must be remembered that for a long period, reaching even a few years, liposarcomas are clinically silent. It happens that in radiological tests sarcomas do not show contrast intensification or give false positive results (these are confused with scar changes after treatment) [17].

In the described case, all radiographic images obtained during the follow-up examinations were analysed; the last CT examination image, taken 30 months after the end of the treatment (surgery and radiotherapy), is identical to the first control CT of the abdominal cavity; it shows no recurrence of cancer and only scar changes.

\section{References}

1. Krzakowski M, Herman K, Jassem J, et al. Onkologia w praktyce klinicznej-zalecenia postępowania diagnostyczno-terapeutycznego w nowotworach złośliwych. Via Medica, Gdańsk 2007.

2. Mankin HJ, Hotnicek FJ. Diagnosis, classification and management of soft tissue sarcomas. Cancer Control 2005; 12: 5-21.

3. Gronchi A, Casali PG, Fiore M, et al. Retroperitoneal soft tissue sarcomas: patterns of recurrence in 167 patients treated at a single institution. Cancer 2004; 100: 2448-55.

4. Guadagnolo BA, Zagars GK, Ballo MT, et al. Excellent local control rates and distinctive patterns failure in myxoid liposarcoma treated with conservation surgery and radiotherapy. Int I Radiat Oncol Biol Phys 2008; 70: 760-5.

5. National Comprehensive Cancer Network. NCCN Soft Tissue Sarcoma Clinical Practice Guidelines. J Natl Compr Canc Netw 2005; 3: 158-94.

6. Bautista N, Su W, O'Connell TX. Retroperitoneal soft tissue sarcoma: prognostic and treatment of primary and recurrent disease. Am Surg 2000; 66: 832-6.

7. Storm FK, Mahvi DM. Diagnosis and management of retroperitoneal soft tissue sarcoma. Ann Surg 1991; 214: 2-10.

8. Ballo MT, Zagars GK, Pollock RE, et al. Retroperitoneal soft tissue sarcoma: an analysis of radiation and surgical treatment. Int I Radiat Oncol Biol Phys 2007; 67: 158-63.

9. Yang JC, Chang AE, Baker AR, et al. Randomized prospective study of the benefit of adjuvant radiation therapy in the treatment of soft tissue sarcomas of the extremity. J Clin Oncol 1998; 16: 197-203.

10. Bradley JC, Caplan R. Giant retroperitoneal sarcoma: a case report and review of the management of retroperitoneal sarcomas. Am Surg 2002; 68: 52-6.

11. Ferrario T, Karakousis CP. Retroperitoneal sarcoma: grade and survival. Arch Surg 2003; 138: 248-51.

12. Pyda P, Paszkowski J, Perz H. Liposarcoma - case report. Pol Przeg Chir 2002; 74: 649-54.

13. Olakowski M, Targosz M, Górka Z. Excision of the abdominal liposarcoma exceeding $11 \mathrm{kgs}$. Pol Przeg Chir 2006; 78: 1025-31.

14. Zagars GK, Ballo MT, Pisters PW, et al. Surgical margins and resection in the management of patients with soft tissue sarcoma using conservative surgery and radiation therapy. Cancer 2003; 97: 2544-53.

15. Alektiar KM, Hu K, Anderson L, et al. High-dose-rate intraoperative radiation therapy (HDR-IORT) for retroperitoneal sarcomas. Int I Radiat Oncol Biol Phys 2000; 47: 157-63.

16. Andrews SF, Anderson PR, Eisanberg BL, et al. Soft tissue sarcomas treated with postoperative external beam radiotherapy with and without low-dose-rate brachytherapy. Int I Radiat Oncol Biol Phys 2004; 59: 475-80.

17. Zlotecki RA, Katz TS, Morris CG, et al. Adjuvant radiation therapy for respectable retroperitoneal soft tissue sarcoma. The University of Florida experience. Am J Clin Oncol 2005; 28: 310-6.

\section{Address for correspondence}

\section{Magdalena Fundowicz}

Greater Poland Cancer Centre

Garbary 15

61-866 Poznań 